\title{
Effect of Antifungal Drugs on Cytochrome P450 (CYP) 1A2, CYP2D6, and CYP2E1 Activities in Human Liver Microsomes
}

\author{
Toshiro Niwa, ${ }^{* a}$ Sachiko Inoue-Yamamoto, ${ }^{b}$ Toshifumi Shiraga, ${ }^{c}$ and Akira Takagi ${ }^{a}$ \\ ${ }^{a}$ Post Marketing Product Development, Astellas Pharma Inc.; 3-4-7 Doshomachi, Chuo-ku, Osaka 541-8514, Japan: \\ ${ }^{b}$ Astellas Research Services Co., Ltd.; 2-1-6 Kashima, Yodogawa-ku, Osaka 532-0031, Japan: and ${ }^{c}$ Drug Metabolism \\ Research Laboratories, Astellas Pharma Inc.; 1-1-8 Azusawa, Itabashi-ku, Tokyo 174-8511, Japan. \\ Received April 12, 2005; accepted May 31, 2005
}

The effects of five antifungal drugs, fluconazole, itraconazole, micafungin, miconazole, and voriconazole, on cytochrome P450 (CYP) 1A2-mediated 7-ethoxyresorufin $O$-deethylation, CYP2D6-mediated debrisoquine 4hydroxylation, and CYP2E1-mediated chlorzoxazone 6-hydroxylation activities in human liver microsomes were compared. In addition, the effect of preincubation was estimated in order to investigate the mechanism-based inhibition. $\mathrm{IC}_{50}$ values of miconazole against CYP1A2 and CYP2D6 activities were 2.90 and $6.46 \mu \mathrm{M}$, respectively, and miconazole at $10 \mu_{\mathrm{M}}$ concentration slightly inhibited CYP2E1 activity. On the other hand, other antifungal drugs neither inhibited nor stimulated all of the metabolic activities. The stimulation of the inhibition of the metabolic activities mediated by CYP1A2, CYP2D6, or CYP2E1 by 15-min preincubation was not observed for any of the antifungal drugs, suggesting that these antifungal drugs are not mechanism-based inhibitors. These results suggest that miconazole is the strongest inhibitor against CYP1A2, CYP2D6, and CYP2E1 among the antifungal drugs investigated.

Key words antifungal drug; fluconazole; itraconazole; micafungin; miconazole; voriconazole

Antifungal drugs, including fluconazole, itraconazole, micafungin, miconazole, and voriconazole, are widely used in the treatment of systemic candidal infections and mycoses. The mechanism of action of these antifungal drugs except for micafungin is the inhibition of fungal cytochrome P450 (CYP, $14 \alpha$-sterol demethylase), an enzyme responsible for the conversion of lanosterol to $14 \alpha$-demethyllanosterol in the ergosterol biosynthetic pathway, ${ }^{1,2}$ whereas micafungin inhibits $1,3-\beta$-D-glucan synthase, leading to disruption of growing fungal cell wall and death of the fungal cell. ${ }^{3,4)}$

Multiple drug therapy is a common therapeutic practice, particularly in patients with several diseases or conditions, and many drug-drug interactions involving metabolic inhibition are being reported. ${ }^{5,6)}$ Recently, we have demonstrated that itraconazole and miconazole, as well as ketoconazole, had higher inhibitory effects on CYP3A4 metabolic activities than fluconazole and micafungin. ${ }^{7)}$ In addition, the $K_{\mathrm{i}}$ values of fluconazole and micafungin against nifedipine oxidation activity, a marker enzyme activity of CYP3A4, have been reported to be $10.7 \mu \mathrm{M}$ and $17.3 \mu \mathrm{M}$, respectively. ${ }^{8)}$ Zhang et al. ${ }^{9)}$ reported that miconazole inhibits several CYPs, including CYP1A2, CYP2C9, CYP2C19, CYP2D6, CYP2E1, and CYP3A4, with $K_{\mathrm{i}}$ values ranging from 0.01 to $7.3 \mu \mathrm{M}$. Furthermore, it is likely that fluconazole and voriconazole inhibit CYP2C9, CYP2C19, and CYP3A4..$^{2,10-13)}$ On the other hand, fluconazole and itraconazole are reported to exhibit no inhibition of CYP2E1, whereas the $K_{\mathrm{i}}$ value of miconazole against CYP2E1 activity is $4 \mu \mathrm{M} .{ }^{14)}$ However, there are few studies comparing the effect of antifungal drugs on the drugmetabolizing activity by human hepatic CYPs, such as CYP1A2, CYP2D6, and CYP2E1, under the same experimental conditions.

Many inhibitors are known to be activated metabolically to a reactive intermediate(s) that, in turn, is irreversibly or quasi-irreversibly bound to the enzyme(s). ${ }^{15)}$ For example, some acetylenes, including those synthetic steroids such as gestodene and ethinyl estradiol, cause mechanism-based inactivation of CYP3A4. ${ }^{16)}$ Sorivudine is converted by gut flora to (E)-5-(2-bromovinyl)uracil (BVU), which is metabolized to dihydro-BVU by dihydropyrimidine dehydrogenase (DPD), and the dihydro-BVU binds to DPD itself. ${ }^{17)}$ Numerous laboratories have indicated that these mechanism-based inactivators exhibit preincubation time-dependence of inhibition. ${ }^{16-27)}$

In the present study, we compared the effects of five antifungal drugs on specific activities by CYP1A2, CYP2D6, and CYP2E1 in human liver microsomes under the same experimental conditions. In addition, the effect of preincubation was estimated in order to investigate whether these antifungal drugs are the mechanism-based inhibitors.

\section{MATERIALS AND METHODS}

Materials Pooled human liver microsomes from 46 or 50 individuals (Lot No. 0210171 or Lot No. 0310241) were obtained from XenoTech (Lenexa, KS, U.S.A.). Micafungin and voriconazole were synthesized in the Medicinal Chemistry Research Laboratories, Fujisawa Pharmaceutical Co., Ltd. Miconazole and fluconazole were purchased from ICN Biomedicals, Inc. (Irvine, CA, U.S.A.) and itraconazole from Janssen-Kyowa (Tokyo, Japan). 7-Ethoxyresorufin, resorufin, debrisoquine sulfate, and chlorzoxazone were obtained from Sigma Chemical Co. (St. Louis, MO, U.S.A.). 4-Hydroxydebrisoquine and 6-hydroxychlorzoxazone were purchased from Sumitomo Chemical Co., Ltd. (Tokyo, Japan), and phenobarbital sodium from Wako Pure Chemicals (Osaka, Japan). All other reagents were of the highest purity commercially available.

Determination of Human CYP Activities 7-Ethoxyresorufin $O$-deethylation activity (CYP1A2), debrisoquine 4hydroxylation activity (CYP2D6), and chlorzoxazone 6-hydroxylation activity (CYP2E1) in human liver microsomes in the presence or absence of antifungal drugs were determined as described previously. ${ }^{28,29)}$ The incubation mixture con- 
sisted of human microsomes, $2 \mathrm{~mm} \mathrm{NADP}^{+}, 10 \mathrm{~mm}$ glucose6-phosphate, $5 \mathrm{~mm}$ magnesium chloride, 1 unit $/ \mathrm{ml}$ of glucose-6-phosphate dehydrogenase, $100 \mathrm{~mm}$ phosphate buffer ( $\mathrm{pH} 7.4$ ), and $5 \mu \mathrm{l}$ of methanol or $0.005-2.5 \mathrm{~mm}$ antifungal drugs dissolved in methanol in a final volume of $500 \mu \mathrm{l}^{28,29)}$ The microsomal protein concentration in the mixture was 0.1 (7-ethoxyresorufin $O$-deethylation), 0.2 (chlorzoxazone 6-hydroxylation) or $0.5 \mathrm{mg} / \mathrm{ml}$ (for debrisoquine 4-hydroxylation). Because the $K_{\mathrm{m}}$ for 7-ethoxyresorufin $O$-deethylation, debrisoquine 4-hydroxylation, and chlorzoxazone 6-hydroxylation by human liver microsomes were $0.22,83.9$, and $47.7 \mu \mathrm{M}$, respectively (data not shown), ${ }^{28,29)}$ the concentrations of 7-ethoxyresorufin, debrisoquine, and chlorzoxazone were $0.25,100$, and $50 \mu \mathrm{M}$, respectively, which are around the expected $K_{\mathrm{m}}$. Incubation was carried out at $37^{\circ} \mathrm{C}$ for $10 \mathrm{~min}$ (for 7-ethoxyresorufin $O$-deethylation and chlorzoxazone 6hydroxylation) or $60 \mathrm{~min}$ (for debrisoquine 4-hydroxylation). For the determination of the effect of preincubation, the maximum concentration of antifungal drugs in the incubation mixture was $10 \mu \mathrm{M}$, because (1) itraconazole more than $1 \mathrm{~mm}$ concentration was not dissolved in methanol and (2) the plasma concentrations of tacrolimus and cyclosporine, which are mainly metabolized by CYP3A $4,{ }^{30)}$ are reported to be unchanged by coadministration of micafungin ${ }^{31,32)}$ despite that the $K_{\mathrm{i}}$ or $\mathrm{IC}_{50}$ of micafungin against CYP3A4 activity is around $10 \mu \mathrm{M} .^{7,8)}$ Preincubation in many studies on the mechanism-based inhibition against CYP activities is conducted for $1-30 \mathrm{~min}$, and obvious preincubation-dependent increases of the inhibition rates are observed in more than 5 10 min preincubation. ${ }^{16,18-26)}$ In addition, Draper et al. examined the inhibitory effects of 5-min preincubation on coumarine 7-hydroxylase (CYP2A6) activity for 47 chemicals, including fluconazole and itraconazole. ${ }^{27)}$ Therefore, the incubation mixture without substrate was preincubated at $37^{\circ} \mathrm{C}$ for $15 \mathrm{~min}$. After preincubation, the substrate was added and then incubated at $37^{\circ} \mathrm{C}$ as mentioned above.

Data Analysis All data were analyzed using the average of duplicate, triplicate, or quadruplicate determinations. In preliminary experiments, the linearity of reaction with incubation time and protein concentration was confirmed for each assay condition. $\mathrm{IC}_{50}$ values were calculated using the WinNonlin Standard computer program (Version 4.1, Pharsight, CA, U.S.A.). Statistical differences for the determination of the effect of preincubation were determined by Student's $t$ test using a program SAS (SAS Institute Inc, Cary, NC, U.S.A.), and the significance level was set at $p<0.05$.

\section{RESULTS}

Effect of Preincubation on Inhibitory Effect of Antifungal Drugs The effects of 15 -min preincubation on the inhibition of antifungal drugs are shown in Figs. 1. Both with and without preincubation, fluconazole, itraconazole, micafungin, and voriconazole at 5 and/or $10 \mu \mathrm{M}$ concentration neither inhibited nor stimulated CYP1A2, CYP2D6, and CYP2E1 activities. Although only miconazole exhibited the inhibition of CYP1A2, CYP2D6, and CYP2E1 activities, the stimulation of the inhibition by 15 -min preincubation was not observed. On the other hand, the slightly decrease of the inhibition by preincubation was observed for fluconazole and itraconazole. These results suggest that all of these drugs are
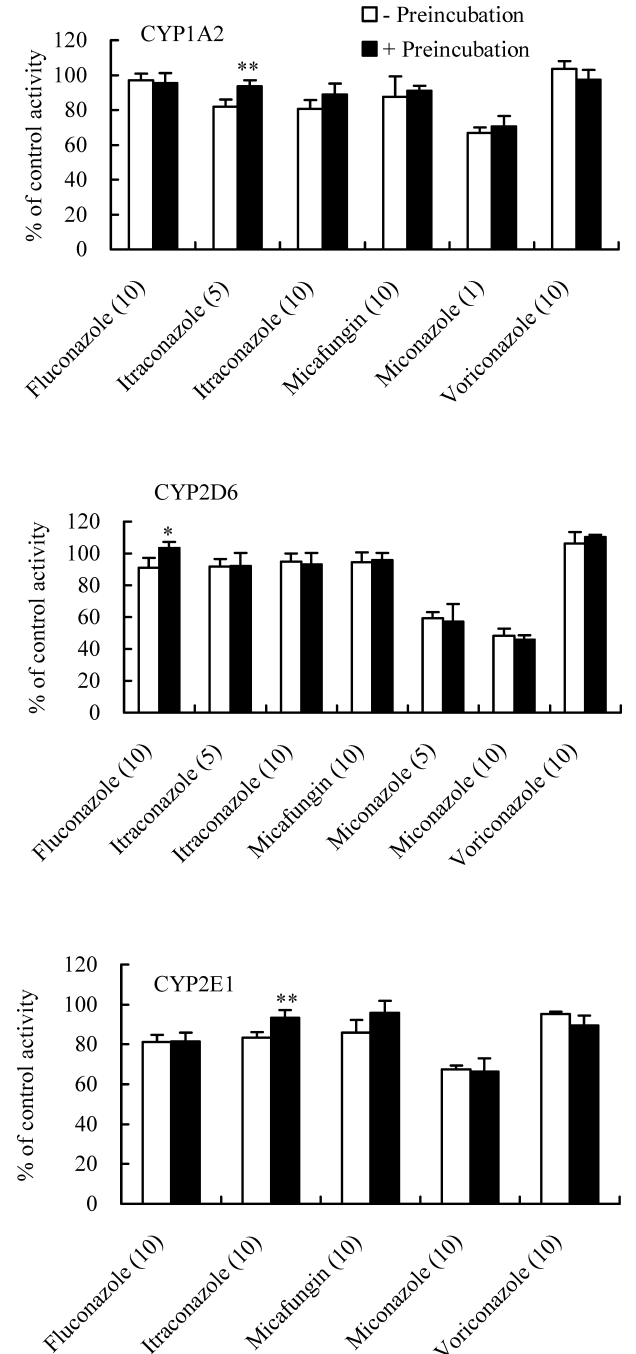

Fig. 1. Effect of Preincubation on the Inhibition of Antifungal Drugs against CYP1A2, CYP2D6, and CYP2E1 Activities in Human Liver Microsomes

The results are shown as means \pm S.D. $(n=3-4)$. Values in parentheses show the concentrations of antifungal drugs $(\mu \mathrm{M}) . * p<0.05, * * p<0.01$.

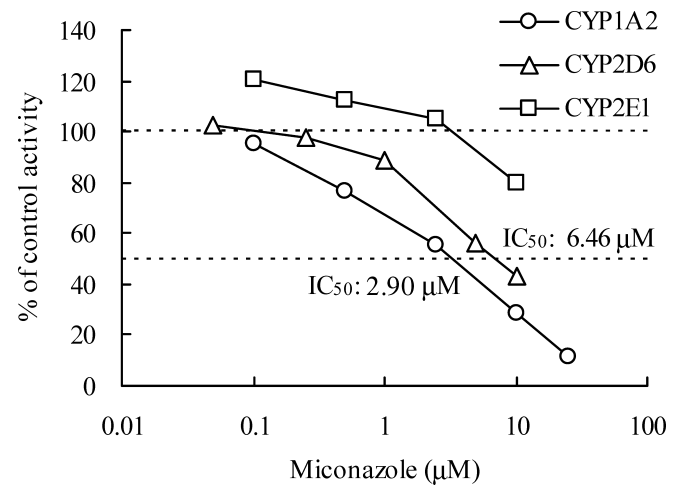

Fig. 2. Effect of Miconazole on CYP1A2, CYP2D6, and CYP2E1 Activities in Human Liver Microsomes

The results are shown as means of duplicate determinations.

not the mechanism-based inhibitors.

Inhibition of CYP Activities by Miconazole Because only miconazole inhibited CYP1A2, CYP2D6, and CYP2E1 activities (Fig. 1), the effects of miconazole concentration on these metabolic activities were investigated (Fig. 2). $\mathrm{IC}_{50}$ val- 
ues against CYP1A2 and CYP2D6 were $2.90 \mu \mathrm{m}$ and $6.46 \mu \mathrm{M}$, respectively.

\section{DISCUSSION}

$\mathrm{IC}_{50}$ values of miconazole against 7-ethoxyresorufin $O$ deethylation (CYP1A2) and debrisoquine 4-hydroxylation (CYP2D6) were $2.90 \mu \mathrm{M}$ and $6.46 \mu \mathrm{m}$, respectively, and miconazole at $10 \mu \mathrm{M}$ concentration inhibited chlorzoxazone 6-hydroxylation (CYP2E1) by $32.5 \%$ (Figs. 1, 2). Zhang et $a l .{ }^{9)}$ reported that the $K_{\mathrm{i}}$ values against CYP1A2, CYP2D6, and CYP2E1 activities are 3.2, 0.70, and 7.3 $\mu \mathrm{M}$, respectively, which are higher than those against CYP2C19 and CYP3A4 $(0.01-0.028 \mu \mathrm{M})$, but similar with those against CYP2C9 $(1.2 \mu \mathrm{M})$, and that miconazole competitively inhibits these activities. On the other hand, Tassaneeyakul et al. ${ }^{14)}$ demonstrated that the $K_{\mathrm{i}}$ value of miconazole against CYP2E1 activity is $4 \mu \mathrm{M}$, and that the inhibition is noncompetitive. Furthermore, Monostory et al. ${ }^{33)}$ reported that miconazole at $250 \mu \mathrm{M}$ concentration has a minor inhibitory effect on CYP2E1 activity. Zhang et al. ${ }^{9)}$ and Monostory et $a l .{ }^{33)}$ conducted chlorzoxazone 6-hydroxylation as a marker of CYP2E1 activity, whereas Tassaneeyakul et al. ${ }^{14)}$ determined 4-nitrophenol hydroxylation activity. The substrate concentrations in all of these papers, ${ }^{9,14,33)}$ as well as our experiments, are around apparent $K_{\mathrm{m}}$. When the substrate concentrations are around the $K_{\mathrm{m}}, K_{\mathrm{i}}$ values are expected to be equal to $\mathrm{IC}_{50} / 2$ or $\mathrm{IC}_{50}$ in competitive or noncompetitive inhibition, respectively. The present observations, on the basis of the inhibitory effect on chlorzoxazone 6-hydroxylation, might be similar to the results reported by Monostory et al ${ }^{33)}$ Thus, miconazole seems to inhibit CYP1A2, CYP2D6, and CYP2E1 activities in the in vitro study. However, there are few clinical interaction studies between miconazole and drugs which are metabolized by these CYPs.

On the other hand, other antifungal drugs neither inhibited nor stimulated CYP1A2, CYP2D6, and CYP2E1 activities at $10 \mu \mathrm{M}$ concentration (Fig. 1). It has been reported that fluconazole and itraconazole are not CYP2E1 inhibitors. ${ }^{14)}$ Recently, we have reported that micafungin $\left(\mathrm{IC}_{50}: 13.5 \mu \mathrm{M}\right)$, as well as fluconazole $\left(\mathrm{IC}_{50}: 13.1 \mu \mathrm{M}\right)$, had lower inhibitory effects on nifedipine oxidation activity, a marker enzyme activity of CYP3A4, than itraconazole $\left(\mathrm{IC}_{50}: 0.0326 \mu \mathrm{M}\right)$, miconazole $\left(\mathrm{IC}_{50}: 0.0742 \mu \mathrm{M}\right)$, and ketoconazole $\left(\mathrm{IC}_{50}: 0.0117 \mu \mathrm{M}\right)$, when the substrate concentration $(10 \mu \mathrm{M})$ was around the $K_{\mathrm{m}}{ }^{7)}$ In addition, the $K_{\mathrm{i}}$ values of micafungin and fluconazole against nifedipine oxidation activity have been reported to be $17.3 \mu \mathrm{M}$ and $10.7 \mu \mathrm{M}$, respectively. ${ }^{8}$ However, the blood concentrations of tacrolimus and cyclosporin, which are mainly metabolized by CYP3A4, ${ }^{30)}$ are not affected by coadministration of micafungin ${ }^{31,32)}$ Therefore, it is possible to speculate that micafungin would not clinically cause drug interactions with other drugs, which are metabolized by CYP1A2 or CYP2D6, or CYP2E1.

Mechanism-based inhibitors have been reported to exhibit preincubation time-dependence of inhibition. ${ }^{16-27)}$ However, the inhibition of CYP1A2-, CYP2D6-, or CYP2E1-mediated reactions by 15 -min preincubation was not stimulated by all of the antifungal drugs investigated (Fig. 1). Therefore, these results suggest that all of antifungal drugs investigated are not the mechanism-based inhibitors. On the other hand, the slightly decrease in the inhibition of CYP1A2-, CYP2D6-, or CYP2E1-mediated reaction by preincubation was observed for itraconazole and fluconazole (Fig. 1). Possible explanation for these phenomena is that these antifungal drugs are metabolized by the microsomes during the preincubation period, thereby lowering the levels of inhibitors prior to assay.

In conclusion, the present study showed that CYP1A2, CYP2D6, and CYP2E1 are inhibited only by miconazole, whereas the inhibition by other antifungal drugs was not observed. In addition, the antifungal drugs investigated are not suggested to be the mechanism-based inhibitors.

\section{REFERENCES}

1) Hitchcock C. A., Dickinson K., Brown S. B., Evans E. G., Adams D. J., Biochem. J., 266, 475-480 (1990).

2) Jeu L., Piacenti F. J., Lyakhovetskiy A. G., Fung H. B., Clin. Ther, 25, 1321-1381 (2003).

3) Yamaguchi H., Nishiyama Y., Uchida K., Hatano K., Morishita Y., Nakai T., Ikeda F, Mutoh S., Jpn. J. Chemother., 50 (Suppl. 1), 20-29 (2002).

4) Fromtling R. A., Drugs Today, 38, 245-257 (2002).

5) Lin J. H., Lu A. Y. H., Clin. Pharmacokinet., 35, 361-390 (1998).

6) Huang S.-M., Lesko L. J., Williams R. L., J. Clin. Pharmacol., 39, 1006-1014 (1999).

7) Sakaeda T., Iwaki K., Kakumoto M., Nishikawa M., Niwa T., Jin J., Nakamura T., Nishiguchi K., Okamura N., Okumura K., J. Pharm. Pharmacol., 57, 759-764 (2005).

8) Kaneko H., Yamato Y., Hashimoto T., Ishii I., Shiraga T., Kawamura A., Terakawa M., Kagayama A., Jpn. J. Chemother., 50 (Suppl. 1), 94-103 (2002).

9) Zhang W., Ramamoorthy Y., Kilicarslan T., Nolte H., Tyndale R. F., Sellers E. M., Drug Metab. Dispos., 30, 314-318 (2002).

10) Venkatakrishnan K., von Moltke L. L., Greenblatt D. J., Clin. Pharmacokinet., 38, 111-180 (2000).

11) Pea F., Furlanut M., Clin. Pharmacokinet., 40, 833-868 (2001).

12) Pearson M. M., Rogers P. D., Cleary J. D., Chapman S. W., Ann. Pharmacother, 37, 420-432 (2003).

13) Kunze K. L., Wienkers L. C., Thummel K. E., Trager W. F., Drug Metab. Dispos., 24, 414-421 (1996).

14) Tassaneeyakul W., Birkett D. J., Miners J. O., Xenobiotica, 28, 293301 (1998).

15) Zhou S., Chan E., Lim L. Y., Boelsterli U. A., Li S. C., Wang J., Zhang Q., Huang M., Xu A., Curr. Drug Metab., 5, 415- 442 (2004).

16) Guengerich F. P., Chem. Res. Toxicol., 3, 363-371 (1990).

17) Kanamitsu S., Ito K., Okuda H., Ogura K., Watabe T., Muro K., Sugiyama Y., Drug Metab. Dispos., 28, 467-474 (2000).

18) Ikeda T., Nishimura K., Taniguchi T., Yoshimura T., Hata T., Kashiyama E., Kudo S., Miyamoto G., Kobayashi H., Kobayashi S., Okazaki O., Hakusui H., Aoyama E., Yoshimura Y., Yamada Y., Yoshikawa M., Otsuka M., Niwa T., Kagayama A., Suzuki S., Satoh T., Xenobio. Metab. Dispos., 16, 115-126 (2001).

19) Chiba M., Nishime J. A., Lin J. H., J. Pharmacol. Exp. Ther, 275, 1527-1534 (1995).

20) Cai Y., Baer-Dubowska W., Ashwood-Smith M. J., Ceska O., Tachibana S., DiGiovanni J., Chem. Res. Toxicol., 9, 729-736 (1996).

21) He K., Woolf T. F., Hollenberg P. F., J. Pharmacol. Exp. Ther, 288, 791-797 (1999).

22) Lin H., Kent U. M., Hollenberg P. F., J. Pharmacol. Exp. Ther, 301, $160-167$ (2002).

23) Khan K. K., He Y. Q., Correia M. A., Halpert J. R., Drug Metab. Dispos., 30, 985-990 (2002).

24) O’Donnell J. P., Dalvie D. K., Kalgutkar A. S., Obach R. S., Drug Metab. Dispos., 31, 1369-1377 (2003).

25) Richter T., Murdter T. E., Heinkele G., Pleiss J., Tatzel S., Schwab M., Eichelbaum M., Zanger U. M., J. Pharmacol. Exp. Ther, 308, 189197 (2004).

26) Iwata H., Tezuka Y., Kadota S., Hiratsuka A., Watabe T., Drug Metab. Dispos., 32, 1351-1358 (2004)

27) Draper A. J., Madan A., Parkinson A., Arch. Biochem. Biophys., 341, 
47-61 (1997).

28) Niwa T., Shiraga T., Yamasaki S., Ishibashi K., Ohno Y., Kagayama A., Xenobiotica, 33, 717-729 (2003).

29) Niwa T., Inoue, S., Shiraga T., Takagi A., Biol. Pharm. Bull., 28, 188-191 (2005).

30) Clarke S. E., Xenobiotica, 28, 1167-1202 (1998).
31) Townsend R., Hebert M., Wisemandle W., Bekersky I., J. Clin. Pharmacol., 42, 1054 (2002).

32) Townsend R., Hebert M., Wisemandle W., Bekersky I., J. Clin. Pharmacol., 42, 1055 (2002).

33) Monostory K., Hazai E., Vereczkey L., Chem.-Biol. Interact., 147, $331-340$ (2004). 